\title{
MODIFIKASI ALGORITMA SEMUT UNTUK OPTIMASI PROBABILITAS PEMILIHAN NODE DALAM PENENTUAN JALUR TERPENDEK
}

\author{
Erlin Windia Ambarsari \\ Program Studi Informatika, Universitas Indraprasta PGRI \\ erlinunindra@gmail.com
}

\begin{abstract}
Abstrak
Berdasarkan laporan pertanggungjawaban penelitian Hibah Dipa LPPM Unindra mengenai pencarian jalur terpendek yang pernah dilakukan penulis pada penelitian sebelumnya dengan judul Analisa Efektifitas Jalur Terpendek Menggunakan Metode Algoritma Semut Dan Pendekatan LeadTime : Studi Kasus Toko Gamis Murah Jakarta pada tahun 2014 masih jauh dari sempurna, terutama pada pemilihan jalur yang dimana dilakukan secara acak sehingga peluang jalur yang keluar dipilih bersifat satu kali dalam satu siklus. Ini akan mengakibatkan iterasi yang dilakukan untuk pencarian jalur terpendek akan lebih lama. Tujuan penelitian ini adalah memodifikasi Algoritma pencarian jalur terpendek dengan menyisipkan Algoritma Fuzzy C-Means ke dalam probabilitas pemilihan titik (node) Algoritma Semut sehingga memungkinkan jalur yang dipilih selama siklus berjalan secara kontinu, sehingga iterasi yang dilakukan dalam perhitungan pencarian jalur terpendek tidak terlalu lama karena lebih cepat mendapatkan konvergensi nilai jalur. Penelitian ini mengambil data kualitatif dari jalur pengiriman barang pelanggan Toko Gamis Murah Jakarta, dimana hasil yang didapatkan adalah Jalur C-G-F-E-D-B-A (32,5 km) dengan probabilitas jalur yang keluar 100\%, D-F-E-G-C-B-A $(34,6 \mathrm{~km})$ dengan probabilitas jalur yang keluar 93,75\% dan F-G-E-D-C-B-A $(37,5 \mathrm{~km})$ dengan probabilitas jalur yang keluar $93,75 \%$.
\end{abstract}

Kata Kunci : Jalur Terpendek, Algoritma Semut, Algoritma Fuzzy C-Means, Probabilitas

\begin{abstract}
LPPM Unindra's Dipa Research Grantprogress report on the searching of the shortest route previously made by the researcher with the title Analysis of the Effectiveness of the Shortest Route Using Ant Algorithm Method and LeadTime Approach: Case Study of Toko Gamis Murah Jakarta in 2014 showsan imperfect route selection, especially the one which is randomly conducted, leading to the chance of output route to be selected is once in a cycle. This causes the iteration conductedtosearch the shortest route will take a longer time. The purpose of this study is to modify the algorithm for finding the shortest route by inserting the Fuzzy $C$-Means Algorithm into node selection probability of the ant algorithm to allow the route chosen during the cycle to continuouslyperform that iteration conducted in the shortest route searching calculation is not too long because the route value convergence is more quickly obtained. This research collects qualitative data from goods delivery route to Toko Gamis Murah Jakarta's customers, with the result showing CGFEDBA route $(32.5 \mathrm{~km})$ with $100 \%$ probability, DFEGCBA (34.6 $\mathrm{km})$ with $93.75 \%$ probability and FGEDCBA $(37.5 \mathrm{~km})$ with $93.75 \%$ probability.
\end{abstract}

Keywords : Shortest Route, Ant Algorithm, Fuzzy C-Means Algorithm, Probability

\section{PENDAhULUAN}

Jalur Terpendek merupakan jalur yang digunakan penggunaan transportasi untuk melakukan perjalanan di mana jalur yang dilalui merupakan jalur dengan jarak yang paling minimum atau terkecil.

Pencarian jalur terpendek dari sejumlah titik tempat yang harus dikunjungi tanpa melalui jalur yang sama. Setiap jalur memiliki karakteristik yang kemungkinan beda dengan jalur yang lain misalnya terdapat jalanan satu jalur, jalan yang sedang diperbaiki, perbedaan waktu pada saat jam sibuk dan lain sebagainya [1].

Berdasarkan laporan pertanggungjawaban penelitian Hibah Dipa LPPM Unindra 
mengenai pencarian jalur terpendek yang pernah dilakukan penulis dengan judul Analisa Efektifitas Jalur Terpendek Menggunakan Metode Algoritma Semut Dan Pendekatan LeadTime : Studi Kasus Toko Gamis Murah Jakarta pada tahun 2014 masih jauh dari sempurna, terutama pada pemilihan jalur yang dimana dilakukan secara acak sehingga peluang (probabilitas) jalur yang keluar dipilih bersifat satu kali dalam satu siklus. Ini akan mengakibatkan iterasi yang dilakukan untuk pencarian jalur terpendek akan lebih lama.

Tujuan penelitian ini adalah memodifikasi Algoritma pencarian jalur terpendek dengan menyisipkan Algoritma Fuzzy $C$ Means ke dalam probabilitas pemilihan titik (node) Algoritma Semut sehingga memungkinkan jalur yang dipilih selama siklus berjalan secara kontinu. Kemudian, manfaat dari penelitian ini adalah iterasi yang dilakukan dalam perhitungan pencarian jalur terpendek tidak terlalu lama karena lebih cepat mendapatkan konvergensi nilai jalur.

\section{A. Jalur Terpendek}

Secara umum dalam penyelesaian masalah pencarian jalur terpendek terdiri dari dua metode, yaitu metode algoritma konvensional dan metode heuristik. Metode algoritma konvensional diterapkan dengan cara perhitungan matematis biasa, sedangkan metode heuristik diterapkan dengan perhitungan kecerdasan buatan dengan menentukan basis pengetahuan dan perhitungannya [2].

1) Metode konvensional yang biasa digunakan untuk melakukan pencarian jalur terpendek, diantaranya Djikstraa, Floyd-Warshall, dan algoritma Bellman-Ford.

2) Metode heuristik adalah sub bidang dari kecerdasan buatan yang digunakan untuk melakukan pencarian dan penentuan optimasi jalur terpendek. Beberapa algoritma pada metode heuristik yang biasa digunakan diantaranya adalah algoritma genetika, algoritma a star,logika fuzzy, neural network, pencarian tabu, simulated anneling,algoritma semut dan lain-lain.

\section{B. Algoritma Semut}

Tujuan Algoritma ini adalah menemukan jalur terpendek berdasarkan jejak kaki lintasan yang telah dilalui semut. Semakin banyak semut melintasi dan meninggalkan feromon, maka akan semakin jelas bekas jejak kakinya. Hal ini menyebabkan lintasan yang dilalui semut dalam jumlah sedikit, semakin lama semakin berkurang kepadatan semut yang melewatinya, atau bahkan tidak dilewati sama sekali. Sebaliknya lintasan yang dilalui semut dalam jumlah banyak, semakin lama akan semakin bertambah kepadatan semut yang melewatinya, atau bahkan semua semut akan melewati lintasan tersebut.

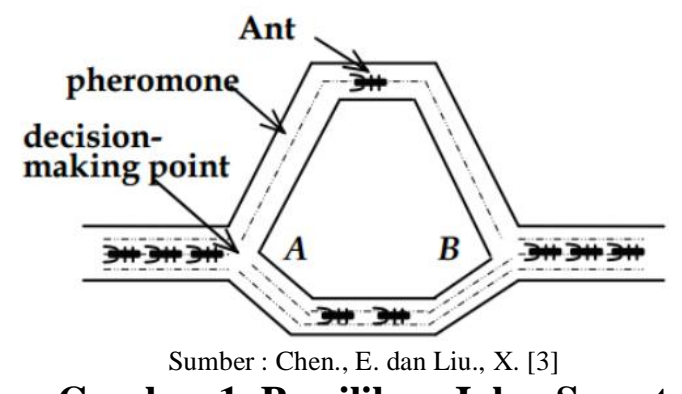

Gambar 1. Pemilihan Jalur Semut

Berdasarkan gambar 1.semut memilih jalurdimulai dari titikA, beberapa semut dapat memilih jalur dari atas atau bawah secara acak dengan kecepatan yang sama menuju titik B. Semut-semut yang memilih jalur bawah akan lebih cepat dibandingkan dengan jalur yangdi atas. Kemudian semutsemut tersebut kembali pada titik A dengan mengikuti jejak feromon yang ditinggalkan sebelumnya, sehingga menyebabkan jumlah feromon pada jalur bawah semakin banyak dan akibatnya jumlah semut yang melewati jalur tersebut akan semakin banyak. Perilaku semut pada algoritma semut untuk menyelesaian permasalahan 
optimasi.Feromon merupakan kunci dasar semut-semut saat membuat keputusan [4]. Langkah-langkah Algoritma Semut untuk menentukan jalur terpendek adalah sebagai berikut :

1) Inisialisasi parameter-parameter dimana

a) Intensitas jejak semut yang menandakan intensitas feromon $\left(\tau_{i j}\right)$

b) Visibilitas jejak $\eta_{i j}=1 / d_{i j}$

c) $\alpha$ tetapan pengendali intensitas

d) $\beta$ tetapan pengendali visibilitas

e) $\rho$ tetapan penguapan jejak semut

f) Q tetapan siklus semut

2) Mengisi jalur pertama ke dalam tabu list yang dilakukan secara acak

3) Menyusun kunjungan setiap semut ke setiap jalur.

4) Menggerakkan semut ke jalur berikutnya dengan menggunakan persamaan probabilitas sebagai berikut:

$$
P_{i j}^{k}=\frac{\left[\tau_{i j}\right]^{\alpha} \cdot\left[\eta_{i j}\right]^{\beta}}{\sum\left[\tau_{i k^{\prime}}\right]^{\alpha} \cdot\left[\eta_{i k^{\prime}}\right]^{\beta}}
$$

5) Menghitung panjang jalur setiap semut $\left(L_{k}\right)$ dilakukan setelah satu siklus diselesaikan oleh semut yang berdasarkan dengan tabu masing masing.

$$
\begin{gathered}
L_{k}=d_{\text {tabu }_{k}(n), \text { tabu }_{k}(1)}+ \\
\sum_{s-1}^{n-1} d_{\text {tabu }_{k}(s), \text { tabu }_{k}(s+1)}
\end{gathered}
$$

dengan $d_{i j}$ adalah jarak antara jalur i ke jalur $\mathrm{j}$ yang dihitung berdasarkan :

$$
d_{i j}=\sqrt{\left(x_{i}-x_{j}\right)^{2}+\left(y_{i}-y_{2}\right)^{2}}
$$

6) Pencarian jalur terpendek berdasarkan harga minimal panjang jarak jalur.

7) Menghitung perubahan intensitas jejak semut dengan meninggalkan feromon pada lintasan yang dilaluinya.

$$
\Delta \tau_{i j}=\sum_{k=1}^{m} \Delta \tau_{i j}^{k}
$$

Setiap semut dihitung berdasarkan persamaan

$$
\Delta \tau_{i j}^{k}=\frac{Q}{L_{k}}
$$

8) Menghitung intensitas feromon semut untuk siklus berikutnya

$$
\tau_{i j}=\rho \tau_{i j}+\Delta \tau_{i j}
$$

9) Menghentikan iterasi jika jumlah siklus sudah maksimum atau konvergensi [2].

\section{Algoritma Fuzzy C-Means}

Fuzzy C-Means (FCM) merupakan metode clustering yang memperbolehkan bagian data mempunyai dua atau lebih cluster (kelompok). Dalam teori fuzzy, keanggotaan sebuah data tidak diberikan nilai secara tegas dengan nilai 1 (menjadi anggota) dan 0 (tidak mencari anggota), melainkan dengan suatu nilai suatu nilai derajat keanggotaan yang jangkauan nilainya 0 sampai dengan 1 .

Jumlah nilai derajat keanggotaan setiap data $\mathrm{x}_{\mathrm{i}}$ selalu dengan 1 , yang diformulasikan pada persamaan berikut :

$$
\sum_{j=1}^{k} u_{i j}=1
$$

Cluster $\mathrm{c}_{\mathrm{j}}$ dapat diformulasikan sebagai berikut :

$$
0<\sum_{j-1}^{k} u_{i j}<n
$$

Nilai derajat keanggotaan data $x_{i}$ pada cluster $\mathrm{c}_{\mathrm{j}}$, diformulasikan pada persamaan berikut

$$
u_{i j}-\frac{D\left(x_{i} c_{j}\right)^{\frac{-2}{w-1}}}{\sum_{i=1}^{k} D\left(x_{i} c_{j}\right)^{\frac{-2}{w-1}}}
$$

Parameter $\mathrm{c}_{\mathrm{j}}$ adalah centroid cluster $\mathrm{ke}-\mathrm{j}$, $\mathrm{D}\left(\mathrm{x}_{\mathrm{i}} \mathrm{c}_{\mathrm{j}}\right)$ adalah jarak antara data dengan centroid, sedangkan $\mathrm{w}$ adalah parameter bobot pangkat (weighting exponent) yang diperkenalkan dalam FCM. w tidak memiliki nilai ketetapan, biasanya nilai w>1 dan umumnya diberi nilai 2 .

Nilai keanggotaan tersebut disimpan dalam matriks fuzzy pseudo-partition berukuran Nxk, dimana baris merupakan data, sedangkan kolom adalah nilai keanggotaan pada setiap cluster. Bentuknya seperti dibawah ini : 


$$
U=\left[\begin{array}{lll}
u_{11}\left[x_{1}\right] & u_{12}\left[x_{1}\right] & u_{1 k}\left[x_{1}\right] \\
u_{21}\left[x_{2}\right] & u_{22}\left[x_{2}\right] & u_{2 k}\left[x_{2}\right] \\
u_{n 1}\left[x_{n}\right] & u_{n 2}\left[x_{n}\right] & u_{n k}\left[x_{n}\right]
\end{array}\right] \text { (10) }
$$

Untuk menghitung centroid pada cluster $\mathrm{c}_{1}$ pada fitur $\mathrm{j}$, digunakan persamaan berikut :

$$
c_{i j}=\frac{\sum_{i=1}^{N}\left(u_{i 1}\right)^{w} x_{i j}}{\sum_{i=1}^{N} D\left(u_{i 1}\right)^{w}}
$$

Parameter $\mathrm{N}$ adalah jumlah data, $\mathrm{w}$ adalah bobot pangkat, dan adalah nilai derajat keanggotaan data $\mathrm{x}_{\mathrm{i}}$ ke cluster $\mathrm{c}_{1}$. Sementara fungsi objektif menggunakan persamaan berikut [5]:

$$
J=\sum_{i=1}^{N} \sum_{j=1}^{k}\left(u_{i j}\right)^{w} D\left(x_{i} c_{i}\right)^{2}
$$

\section{METODE PENELITIAN}

Penelitian ini merupakan pengembangan penelitian terdahulu [1] dan data yang diambil adalah data kualitatif dari jalur pengiriman barang pelanggan Toko Gamis Murah Jakarta dan moda transportasi digunakan sebagai salah satu instrumen penelitian adalah kendaraan bermotor yang dilakukan pada bulan Februari sampai dengan bulan Mei tahun 2014 dengan mengambil titik koordinat dari Google map dan Track Record. Hasil sampel data kemudian dihitung dengan Algoritma Semut.

Langkah-langkah Algoritma Semut yang dilakukan pada penelitian tersebut sebagai berikut :

a) Inisialisasi dan pengisian jalur dilakukan secara acak

b) Menyusun kunjungan setiap semut (Ant) ke setiap jalur.

c) Menggerakkan semut ke titik (node) jalur berikutnya (dilakukan secara acak)

d) Menghitung panjang jalur setiap semut setelah satu siklus diselesaikan.

e) Menghitung intensitas feromon semut untuk siklus berikutnya.

f) Siklus akan berhenti jika sudah maksimum atau konvergensi.
Kemudian langkah-langkah diatas dimodifikasi dengan cara menyisipkan Algoritma FCM ke dalam nilai acak pemilihan jalur (langkah c), yang akan di jelaskan pada langkah-langkah Algoritma sebagai berikut sebagai berikut :

a) Inisialisasi dan pengisian jalur dilakukan secara acak

b) Menyusun kunjungan setiap semut (Ant) ke setiap jalur.

c) Menggerakkan semut ke titik (node) jalur berikutnya

1) Inisialisasi : tentukan jumlah cluster $(\mathrm{k} \geq 2)$, tentukan bobot pangkat $(\mathrm{w}>1)$, tentukan jumlah maksimal iterasi, tentukan ambang batas perubahan nilai fungsi objektif (jika perlu juga perubahan nilai centroid).

2) Berikan nilai awal pada matriks fuzzy pseudo-partition.

3) Lakukan langkah iv sampai v selama syarat dipenuhi : apabila perubahan pada nilai fungsi objektif masih diatas nilai ambang batas yang ditentukan; atau perubahan pada nilai centroid masih diatas nilai ambang batas yang ditentukan; atau iterasi maksimum belum tercapai.

4) Hitung nilai centroid dari masing masing cluster.

5) Hitung kembali matriks fuzzy pseudo partition (derajat keanggotaan setiap data pada setiap cluster) [5]

d) Mengambil nilai derajat keanggotaan tertinggi pada semua cluster sebagai titik (node) jalur yang akan diambil oleh semut.

e) Menghitung panjang jalur setiap semut setelah satu siklus diselesaikan.

f) Menghitung intensitas feromon semut untuk siklus berikutnya

g) Siklus akan berhenti jika sudah maksimum atau konvergensi [6].

Penggunaan algoritma semut yang dihubungkan dengan Fuzzy $C$ - 
Meanstersebut dilakukan pengelompokkan (cluster) fuzzy.Salah satu aspeknya adalah ketahanan dari algoritma semut dapat mempertahankan sensibilitas inisialisasi Fuzzy C-Means. Di sisi lain, komputasi paralel dan terdistribusi dari algoritma koloni semut mempercepat konvergensi dan meningkatkan efisiensi pengelompokan. Fuzzy C-Means adalah salah satu algoritma pengelompokan fuzzy dan dapat memberikan tingkat keanggotaan masing-masing sampel data [7].

\section{HASIL DAN PEMBAHASAN}

Sebelum membahas mengenai hasil modifikasi titik (node) Algoritma Semut, perlu baiknya melihat keluaran pencarian jalur pendek pada penelitian sebelumnya [1] pada tabel 2dengan sampel data sebagai berikut :

Tabel 1 Titik Sampel Data

\begin{tabular}{|c|c|}
\hline Titik/Node & Sumber \\
\hline $\mathrm{A}$ & $\begin{array}{c}\text { J1 Pule No 27-30, Ciracas } \\
\text { Kota Jakarta Timur, DKI } \\
\text { Jakarta } 13740 \\
\end{array}$ \\
\hline B & $\begin{array}{l}\text { Jl Kenanga } 1 \text { Kalisari } \\
\text { Ciracas Jakarta Timur }\end{array}$ \\
\hline $\mathrm{C}$ & $\begin{array}{l}\text { J1 Tegal Parang Mampang } \\
\text { Prapatan Jakarta Selatan }\end{array}$ \\
\hline $\mathrm{D}$ & $\begin{array}{c}\text { Jl H. Jian No.90 Cipete } \\
\text { Utara Jakarta Selatan } \\
12150 \\
\end{array}$ \\
\hline $\bar{E}$ & $\begin{array}{c}\text { Jl Prapanca Buntu } \\
\text { (Ciciero) Cipete Utara } \\
\text { Jakarta Selatan } 12150\end{array}$ \\
\hline $\mathrm{F}$ & $\begin{array}{c}\text { Jl Sultan Iskandarsyah } 2 \\
\text { No. } 96 \text { Blok M Jakarta } \\
\text { Selatan }\end{array}$ \\
\hline G & $\begin{array}{l}\text { Jl. Karet Pedurenan No. } \\
\text { 12-25 Setiabudi Jakarta } \\
\text { Selatan }\end{array}$ \\
\hline
\end{tabular}

Tabel 2 Pencarian Jalur Terpendek Siklus 14 s/d 16.

Siklus
14
\begin{tabular}{|l|l|l|l|l|l|l|l|r|r|}
\hline Semut & \multicolumn{7}{|c|}{ Path } \\
\hline S1 & A & G & B & E & D & C & F & 57.8 & 0.017301 \\
\hline S2 & B & A & G & C & F & D & E & 32.1 & 0.031153 \\
\hline S3 & C & E & F & D & A & B & G & 45.2 & 0.022124 \\
\hline S4 & D & E & F & G & C & A & B & 29.3 & 0.03413 \\
\hline S5 & E & C & D & F & G & A & B & 38.4 & 0.026042 \\
\hline S6 & F & C & E & G & D & A & B & 41.1 & 0.024331 \\
\hline S7 & G & E & F & D & A & C & B & 50.2 & 0.01992 \\
\hline
\end{tabular}

\section{Siklus}

15

\begin{tabular}{|l|l|l|l|l|l|l|l|r|r|}
\hline Semut & \multicolumn{9}{|c|}{ Path } \\
\hline S1 & A & E & B & D & G & F & C & 60.5 & 0.016529 \\
\hline S2 & B & F & A & E & C & D & G & 60.8 & 0.016447 \\
\hline S3 & C & D & G & F & E & A & B & 38.3 & 0.02611 \\
\hline S4 & D & G & E & B & C & F & A & 62 & 0.016129 \\
\hline S5 & E & D & F & C & A & G & B & 52.3 & 0.01912 \\
\hline S6 & F & C & G & E & D & A & B & 33.3 & 0.03003 \\
\hline S7 & G & C & D & F & E & A & B & 31.7 & 0.031546 \\
\hline
\end{tabular}

Siklus
\begin{tabular}{|l|l|l|l|l|l|l|l|r|l|}
16 & Jarak & $\Delta$ ti,j \\
\hline Semut & \multicolumn{7}{|c|}{ Path } \\
\hline S1 & A & G & C & B & E & D & F & 51.5 & 0.019417 \\
\hline S2 & B & G & A & C & F & D & E & 52.4 & 0.019084 \\
\hline S3 & C & B & A & F & D & G & E & 50.5 & 0.019802 \\
\hline S4 & D & G & E & C & F & A & B & 42.5 & 0.023529 \\
\hline S5 & E & D & B & F & G & C & A & 53.5 & 0.018692 \\
\hline S6 & F & E & C & D & A & B & G & 46.6 & 0.021459 \\
\hline S7 & G & F & C & E & D & A & B & 33.8 & 0.029586 \\
\hline
\end{tabular}

Iterasi dilakukan dari Siklus 1 sampai dengan Siklus 16 dengan pengendali intensitas $(\alpha)=1$, pengendali visibilitas $(\beta)$ $=1$, penguapan jejak semut $(\rho)=0.5$, intensitas feromon $(\tau \mathrm{ij})=0.01$, keluaran titik Jalur tidak ada yang sama setiap siklus. Penyebab terjadinya ketidaksamaan keluaran titik dikarenakan pemilihan jalur 
dari probabilitas pada persamaan 1 menggunakan nilai acak.

Kemudian ketikadilakukan modifikasi Algoritma Semut dengan penyisipan Algoritma FCM ke dalam pemilihan titik (node) dengan ketetapan yang sama dengan penelitian sebelumnya dimana hasil yang didapatkan adalah sebagai berikut :

\section{Tabel 3. Modifikasi Pencarian Jalur Terpendek Siklus 14 s/d 16}

\section{Siklus}

14

\begin{tabular}{|l|l|l|l|l|l|l|l|r|l|}
\hline Semut & \multicolumn{7}{|c|}{ Path } & Jarak & $\Delta$ ti,j \\
\hline S1 & A & F & E & D & G & C & B & 42.4 & 0.023585 \\
\hline S2 & B & F & E & D & G & C & A & 42.4 & 0.023585 \\
\hline S3 & C & G & F & E & D & B & A & 32.5 & 0.030769 \\
\hline S4 & D & F & E & G & C & B & A & 34.6 & 0.028902 \\
\hline S5 & E & F & G & D & C & B & A & 39.4 & 0.025381 \\
\hline S6 & F & G & E & D & C & B & A & 37.5 & 0.026667 \\
\hline S7 & G & F & D & C & E & B & A & 39.1 & 0.025575 \\
\hline
\end{tabular}

Siklus
15
\begin{tabular}{|l|l|l|l|l|l|l|l|r|l|} 
Semut & \multicolumn{7}{|c|}{ Path } & Jarak & $\Delta$ ti,j \\
\hline S1 & A & F & E & D & G & C & B & 42.4 & 0.023585 \\
\hline S 2 & B & F & E & D & G & C & A & 42.4 & 0.023585 \\
\hline S3 & C & G & F & E & D & B & A & 32.5 & 0.030769 \\
\hline S4 & D & F & E & G & C & B & A & 34.6 & 0.028902 \\
\hline S5 & E & F & G & D & C & B & A & 39.4 & 0.025381 \\
\hline S6 & F & G & E & D & C & B & A & 37.5 & 0.026667 \\
\hline S7 & G & F & D & C & E & B & A & 39.1 & 0.025575 \\
\hline & & \multicolumn{7}{|c|}{ Jalur Terbaik } & 0.030769 \\
\hline
\end{tabular}

Siklus
\begin{tabular}{|l|l|l|l|l|l|l|l|r|l|} 
16 \\
Semut & \multicolumn{7}{|c|}{ Path } & Jarak & $\Delta$ ti,j \\
\hline S1 & A & F & E & D & G & C & B & 42.4 & 0.023585 \\
\hline S2 & B & F & E & D & G & C & A & 42.4 & 0.023585 \\
\hline S3 & C & G & F & E & D & B & A & 32.5 & 0.030769 \\
\hline S4 & D & F & E & G & C & B & A & 34.6 & 0.028902 \\
\hline S5 & E & F & G & D & C & B & A & 39.4 & 0.025381 \\
\hline S6 & F & G & E & D & C & B & A & 37.5 & 0.026667 \\
\hline S7 & G & F & D & C & E & B & A & 39.1 & 0.025575 \\
\hline
\end{tabular}

Penyebab banyaknya peluang keluaran titik saat pemilihan jalur dikarenakan dilakukan optimasi probabilitas titik dengan cara membagi 3 cluster dan kemudian dihitung nilai centroid-nya sehingga mendapatkan nilai derajat keanggotaan. Pemilihan titik jalur dilakukan dengan mengambil nilai derajat keanggotaan tertinggi sehingga pemilihan titik tersebut menjadi optimal.

Pada penelitian ini nilai derajat keanggotaan yang didapatkan dari perhitungan Algoritma FCM dengan nilai kesalahan (error) adalah 0,013374342 dengan 10 iterasi sebagai berikut :

\section{Tabel 4. Nilai Maksimum Derajat} Keanggotaan Untuk 3 Cluster

\begin{tabular}{|c|c|c|}
\hline \multicolumn{3}{|c|}{ Sum } \\
\hline $\mathbf{c}_{\mathbf{1}}$ & $\mathbf{c}_{\mathbf{2}}$ & $\mathbf{c}_{\mathbf{3}}$ \\
\hline 820.1553 & 742.8075 & 19.49429 \\
\hline 1100.757 & 998.0309 & 18.51219 \\
\hline 71.20108 & 19.91559 & 812.1208 \\
\hline 3.979824 & 114.1216 & 906.5148 \\
\hline 1.528156 & 108.0131 & 955.9006 \\
\hline 12.78706 & 77.09307 & 1007.749 \\
\hline 137.723 & 10.6059 & 906.2848 \\
\hline
\end{tabular}

\begin{tabular}{|c|c|c|c|}
\hline \multicolumn{3}{|c|}{ Sum $^{-\mathbf{1}(\mathbf{w}-\mathbf{1})}$} & \multirow{2}{*}{ Total } \\
\hline $\mathbf{c}_{\mathbf{1}}$ & $\mathbf{c}_{\mathbf{2}}$ & $\mathbf{c}_{\mathbf{3}}$ & \\
\hline 0.001219 & 0.001346 & 0.051297 & 0.053862601 \\
\hline 0.000908 & 0.001002 & 0.054018 & 0.055928906 \\
\hline 0.014045 & 0.050212 & 0.001231 & 0.065487992 \\
\hline 0.251267 & 0.008763 & 0.001103 & 0.261133117 \\
\hline 0.654383 & 0.009258 & 0.001046 & 0.664687703 \\
\hline 0.078204 & 0.012971 & 0.000992 & 0.092167728 \\
\hline 0.007261 & 0.094287 & 0.001103 & 0.102651531 \\
\hline
\end{tabular}

\begin{tabular}{|c|c|c|c|}
\hline $\mathbf{c}_{\mathbf{1}}$ & $\mathbf{c}_{\mathbf{2}}$ & $\mathbf{c}_{\mathbf{3}}$ & MAX C \\
\hline 0.022637 & 0.02499404 & 0.952369081 & 0.952369081 \\
\hline 0.016243 & 0.01791512 & 0.965841654 & 0.965841654 \\
\hline 0.214463 & 0.76673471 & 0.018802591 & 0.766734711 \\
\hline 0.96222 & 0.03355599 & 0.004224382 & 0.962219624 \\
\hline 0.984498 & 0.01392855 & 0.001573873 & 0.984497577 \\
\hline 0.848497 & 0.14073618 & 0.010766354 & 0.848497467 \\
\hline 0.070734 & 0.91851698 & 0.010749044 & 0.918516983 \\
\hline
\end{tabular}

Jalur yang terpendek yang di hasilkan pada penelitian ini adalah C-G-F-E-D-B-A (lihat tabel 3) dengan jarak 32,5. Berbeda sekali dengan jalur terpendek yang dihasilkan pada penelitian sebelumnya yaitu G-C-FE-D-A-B dengan jarak 28,8. Ini dikarenakan pemilihan probabilitas titik 
jalur semut berdasarkan perhitungan centroid dari Algoritma FCM, namun kesempatan peluang keluarnya titik jalur yang sama lebih banyak. Berikut adalah jalur yang dipilih dari modifikasi Algoritma Semut beserta probabilitas jalur yang keluar.

Tabel 5. Presentasi Probabilitas Jalur

\begin{tabular}{|c|c|c|}
\hline \multicolumn{3}{|c|}{ Siklus 1 s/d 16} \\
\hline Path & $\begin{array}{c}\text { Probabilitas } \\
\text { Jalur yang } \\
\text { Keluar }(\%)\end{array}$ & Siklus \\
\hline A-G-F-E-D-C-B & 25 & $1,2,3,12$ \\
\hline A-F-E-G-D-C-B & 12.5 & 4,5 \\
\hline A-F-E-D-G-C-B & 62.5 & $\begin{array}{l}6,7,8,9,10,11, \\
13,14,15,16\end{array}$ \\
\hline B-G-F-E-D-C-A & 25 & $1,2,3,12$ \\
\hline B-F-G-E-D-C-A & 6.25 & 4 \\
\hline B-F-E-G-D-C-A & 6.25 & 5 \\
\hline B-F-E-D-G-C-A & 62.5 & $\begin{array}{l}6,7,8,9,10,11, \\
13,14,15,16\end{array}$ \\
\hline $\begin{array}{l}\text { C-G-F-E-D-B- } \\
\text { A }\end{array}$ & 100 & $\begin{array}{l}1,2,3,4,5,6,7, \\
8,9,10,11,12 \\
13,14,15,16\end{array}$ \\
\hline D-G-F-E-C-B-A & 6.25 & 1 \\
\hline $\begin{array}{l}\text { D-F-E-G-C-B- } \\
\text { A }\end{array}$ & 93.75 & $\begin{array}{l}2,3,4,5,6,7,8 \\
9,10,11,12,13 \\
14,15,16\end{array}$ \\
\hline E-G-F-D-C-B-A & 25 & $1,2,3,4$ \\
\hline E-F-G-D-C-B-A & 68.75 & $\begin{array}{l}5,6,7,8,9,10 \\
11,13,14,15,16\end{array}$ \\
\hline E-F-D-G-C-B-A & 6.25 & 12 \\
\hline F-E-G-D-C-B-A & 6.25 & 1 \\
\hline $\begin{array}{l}\text { F-G-E-D-C-B- } \\
\text { A }\end{array}$ & 93.75 & $\begin{array}{l}2,3,4,5,6,7,8, \\
9,10,11,12,13, \\
14,15,16\end{array}$ \\
\hline G-F-E-D-C-B-A & 18.75 & $1,2,3$ \\
\hline G-F-D-E-C-B-A & 6.25 & 4 \\
\hline G-F-D-C-E-B-A & 68.75 & $\begin{array}{l}5,6,7,8,9,10, \\
11,13,14,15, \\
16\end{array}$ \\
\hline G-F-C-E-D-B-A & 6.25 & 12 \\
\hline
\end{tabular}

Pemilihan jalur terpendek yang didapatkan berdasarkan banyaknya jalur yang keluar sebagai berikut :
1) Jalur C-G-F-E-D-B-A dengan probabilitas jalur yang keluar $100 \%$
2) Jalur D-F-E-G-C-B-A dengan probabilitas jalur yang keluar $93,75 \%$
3) Jalur F-G-E-D-C-B-A dengan probabilitas jalur yang keluar $93,75 \%$

Simpulan yang didapatkan dari penelitian ini adalah jalur terpendek untuk pengiriman barang pelanggan Toko Gamis Murah Jakarta antara lain jalur C-G-F-ED-B-A dengan jarak 32,5 km; jalur D-F-EG-C-B-A dengan jarak 34,6 km; dan jalur F-G-E-D-C-B-A dengan jarak $37,5 \mathrm{~km}$ (lihat pada tabel 3).

\section{SIMPULAN}

Berdasarkan hasil pengolahan data dari modifikasi Algoritma Semut dapat diperoleh simpulan sebagai berikut :

1) Penyebab banyaknya peluang keluaran titik saat pemilihan jalur dikarenakan dilakukan optimasi probabilitas titik dengan cara membagi 3 cluster dan kemudian dihitung nilai centroid-nya sehingga mendapatkan nilai derajat keanggotaan. Pemilihan titik jalur dilakukan dengan mengambil nilai derajat keanggotaan tertinggi sehingga pemilihan titik tersebut menjadi optimal.

2) Pemilihan probabilitas titik jalur semut berdasarkan perhitungan centroid dari Algoritma FCM, sehingga kesempatan peluang keluarnya titik jalur yang sama lebih banyak.

3) Kesimpulan yang didapatkan dari penelitian ini adalah jalur terpendek untuk pengiriman barang pelanggan Toko Gamis Murah Jakarta antara lain jalur C-G-F-E-D-B-A dengan jarak $32,5 \mathrm{~km}$ (100\% probabilitas); jalur DF-E-G-C-B-A dengan jarak 34,6 km (93,75\% probabilitas); dan jalur F-G-ED-C-B-A dengan jarak $37,5 \mathrm{~km}$ (93,75\% probabilitas).

\section{UCAPAN TERIMAKASIH}

Penulis mengucapkan terima kasih kepada rekan tim Bapak Arif Susanto dan Ibu Dwi Marlina yang ikut andil dalam penelitian Analisa Efektifitas Jalur Terpendek Dengan Menggunakan Metode Algoritma Semut Dan Pendekatan LeadTime pada tahun 2014, serta Gravita Alfiani yang bersedia membantu menyelesaikan penelitian ini. 


\section{DAFTAR PUSTAKA}

[1] Ambarsari, E.W., Marlina, D., dan Susanto, A. Analisa Efektifitas Jalur Terpendek Dengan Menggunakan Algoritma Semut Dan Pendekatan LeadTime : Studi Kasus Toko Gamis Murah Jakarta. Laporan Pertanggung Jawaban Penelitian Hibah Dipa LPPM Unindra.Jakarta : LPPM Unindra. 2014.

[2] Mutakhiroh, I., Indrato.,dan Hidayat, T. Pencarian Jalur Terpendek Menggunakan Algoritma Semut. Seminar Nasional Aplikasi Teknologi Informasi 2007 (SNATI 2007). B-81B-85. 2007.

[3] Chen, E.dan Liu, X. Multi-Colony Ant Algorithm. In Ant Colony Optimization-Methods and Applications. Pengeditan oleh Avi Ostfeld. InTech. 2011.

[4] Ismail, A.A., Herdjunanto, S., dan Priyatmadi. Penerapan Algoritma Ant
System Dalam Menemukan Jalur Optimal Pada Traveling Salesman Problem (TSP) Dengan Kekangan Kondisi Jalan. JNTETI. 1(3) : 43-48. 2012.

[5] Astria, D., dan Suprayogi. Penerapan Algoritma Fuzzy C-Means Untuk Clustering Pelanggan Pada CV. Mataram Jaya Bawen, Eksplora Informatika. 6(2) : 169-178. 2017.

[6] Kanade, P. M., dan Hall, L. O. Fuzzy ants as a clustering concept. In Fuzzy Information Processing Society. 22nd International Conference of the North American. NAFIPS. IEEE. 227-232. 2003.

[7] Krishnan, P.H., dan Ramamoorthy, DR. P. Fuzzy Clustering Based Ant Colony Optimization Algorithm For $\mathrm{Mr}$ Brain Image Segmentation, Journal of Theoretical and Applied Information Technology. 65(3) : 644649. 2014. 